\title{
REFLEXÕES SOBRE MUNDO DIGITAL E SUBJETIVIDADE
}

\author{
Reflections on digital world and subjectivity \\ Reflexiones sobre el mundo digital y la subjetividad
}

\begin{abstract}
RESUMo O objetivo deste ensaio é apresentar questões urgentes a respeito da relação entre o mundo digital que configura a sociedade atual, a partir do avanço ao acesso às tecnologias computacionais, e a emergência de subjetividades específicas que respondem antropologicamente aos aparatos que fomentam sua realização. Levo à reflexão crítica o conceito de digital a partir da ideia de dígitos, sua lógica matemática clássica e contraposição ao analógico, avançando para a ideia insurgente de computação quântica, e enfatizo a necessidade de se pensar essas questões a partir de uma teoria crítica da tecnologia. Prossigo com aspectos históricos do desenvolvimento dos meios de comunicação, que ajudam a compreender como, embora cada nova tecnologia de comunicação tenha surgido com a promessa de emancipação e liberdade, tal promessa jamais foi realizada, na medida em que o modo de produção em voga direciona seu desenvolvimento em prol de sua manutenção. Tal direcionamento não ocorre apenas para com os artefatos, mas com eles e por meio deles, também em relação ao desenvolvimento das subjetividades aqui e agora, no surgimento dos computer people como tipo antropológico da sociedade digital, correlato à geração do rádio, pensado por Theodor W. Adorno nos anos 1930. Finalizo com as possibilidades de práxis frente às questões colocadas.
\end{abstract}

PalaVRas-Chave: TEORIA CRítICA DA SOCIEDADE. TECNOlOGIA. MUNDO DIGITAL. COMPUTER PEOPLE.

ABSTRACT The objective of this essay is to present urgent questions about the relationship between the digital world that shapes our present society, from the advance to the access to computational technologies, and the emergence of specific subjectivities that respond anthropologically to the apparatuses that foster its realization. It begins by bringing to the critical reflection the concept of digital from the idea of digits, its classical mathematical logic and counterposition to the analogical one, advances towards the insurgent idea of quantum computation, and presents the necessity to think these questions from a critical theory of technology. I continue by bringing historical aspects of the development of the media, which help us understand how, although each new communication technology has emerged with the promise of emancipation and freedom, such a promise has
Deborah Christina Antunes ${ }^{\mathrm{I}}$ IUniversidade Federal do Ceará (UFC), Fortaleza/CE - Brasil

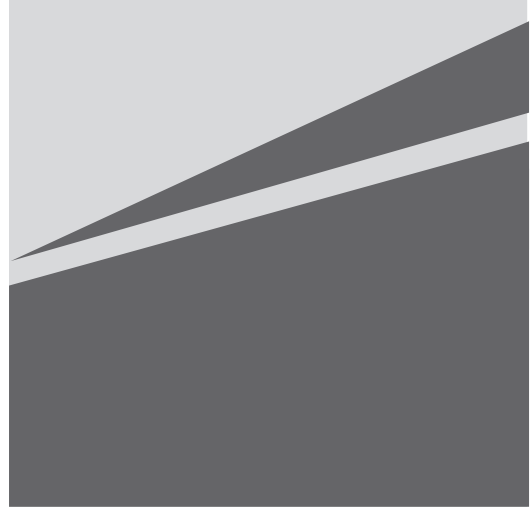


never been fulfilled, since the mode of production in vogue directs its development for the sake of its maintenance. Such a direction does not only occur with the artifacts, but with them and through them, also in relation to the development of the subjectivities here and now, in the emergence of computer people as an anthropological type of the digital society, correlated to the radio generation, thought by Theodor W. Adorno in the 1930s. I finish with the possibilities of praxis in the face of the questions posed.

KEY-WORDS: CRITICAL THEORY OF SOCIETY. TECHNOLOGY. DiGiTAL WORLD. COMPUTER PEOPLE.

RESUMEN El propósito de este ensayo es presentar preguntas urgentes sobre la relación entre el mundo digital que da forma a nuestra sociedad, desde el acceso anticipado a las tecnologías informáticas, y la emergencia de subjetividades específicas que responden antropológicamente a los dispositivos que favorezcan su logro. Inicio con la reflexión crítica del concepto de digital a partir de la idea dígitos, su lógica matemática clásica y opuesto a analógico, avanzando a la idea insurgente de la computación cuántica, y presento la necesidad de pensar en estos temas desde una teoría crítica de la tecnología. Sigo trayendo aspectos históricos del desarrollo de los medios de comunicación, que ayudan a entender cómo, a pesar de que cada nueva tecnología de la comunicación ha surgido con la promesa de la emancipación y la libertad, tal promesa nunca fue hecha, en la medida en que el modo de producción dirige su desarrollo hacia su mantenimiento. Esta guía no sólo se produce hacia los artefactos, pero con ellos y a través de ellos, también para el desarrollo de las subjetividades aquí y ahora, la emergencia de las computer people como tipo antropológico de la sociedad digital, correlativa a la generación de radio, diseñado por T. Adorno en la década de 1930. Finalizo con las posibilidades de la praxis frente a las preguntas postas.

Palavras Clave: Teoría Crítica de la Sociedad. TeCnología. Mundo digitAl. Computer PeOPle.

\section{INTRODUÇÃo}

- ste ensaio surgiu a partir de diversas inquietações e questionamentos advindos da vida na sociedade tecnológica digital e da informação que tem se desenhado e ganhado hegemonia nas últimas décadas. Ele tenta elaborar alguns temas trabalhados em projeto de pesquisa, ${ }^{1}$ cujo objetivo é pensar um novíssimo tipo antropológico de homem no mundo digital, a partir de alguns insights adornianos e de sua análise do rádio como meio tecnológico de sua época e da geração do rádio. Tais inquietações e questionamentos reverberam uma experiência e um estranhamento que se situam na transição de um momento em que computadores pessoais eram artigos inimagináveis, e outro muito recente em que eles não apenas estão em todos os espaços da vida - trabalho, entretenimento, saúde, educação, relações interpessoais - redesenhando-se de formas e tamanhos

\footnotetext{
A pesquisa em questão é financiada pela FUNCAP, processo n. BP2-0107-00067.01.00/15.
}

diversos, como parecem direcionar modos de pensar e agir frente a problemáticas contemporâneas contraditórias e complexas. Este texto foi elaborado para a mesa de abertura do "II Simpósio Internacional de Teoria Crítica e I Encontro Nexos: Teoria Crítica e Pesquisa Interdisciplinar - As Vicissitudes da Experiência no mundo digital", e por isso é apresentado para compor este dossiê. Além disso, procura lançar luz a respeito do trabalho que a rede de pesquisa Nexos tem desenvolvido a partir do reconhecimento das contradições do desenvolvimento tecnológico no mundo contemporâneo em tempos de neoliberalismo acadêmico, ${ }^{2}$ de flexibilização dos direitos sociais e espaços de trabalho que ganham nesse desenvolvimento tecnológico sua base material de realização, suprimindo diferenças e dando continuidade ao processo de colonização dos diferentes grupos sociais.

A realidade daquilo que se tem usado chamar de "novas mídias" perpassa nossa

PUELLO-SOCARRÁS, 2011; BERI \& TELLO, 2005. 
existência nas mais diversas ocasiões: desde a prática do trabalho físico e reflexão intelectual, às manifestações políticas - vide a efervescência dos debates nas chamadas redes sociais virtuais, que cresceu exponencialmente a partir de junho de 2013 no Brasil $^{3}$-, desde o cotidiano nas cidades e no campo, aos eventos científicos, desde os "momentos de lazer" e entretenimento, ou "tempo livre", 4 até o momento de formação geral e profissional e de cuidado com a saúde e controle dos corpos - que sabemos que não é somente dos corpos e aqui também a separação entre corpo e mente que tanto marca nossa racionalidade ocidental serve a uma visão enevoada daquilo que vivemos. Todas as cicatrizes que carregamos, no físico ou no metafísico, e aqui eu faço referência à metapsicologia, determinam-se mutuamente e fundamentam nossa existência.

O tema "As Vicissitudes da Experiência no mundo digital" tem, ao menos, três ideias, as quais eu destaco nesse momento de abertura do nosso diálogo: a ideia de vicissitudes, a questão da experiência, e a realidade de um mundo digital. Iniciarei aqui pela última, na qual vou me deter um pouco mais para dela derivar questões sobre as possibilidades e as variações da experiência da subjetividade contemporaneamente.

\section{MUNDO DIGITAL E SUAS SIGNIFICAÇÕES}

O que significa falar em um "mundo digital"? A literatura sociológica/filosófica costuma apresentar a definição de "digital" em contraposição à de "analógico". De Pierre Levy (2010) a Gilles Deleuze (2010), pensadores com atitudes diferentes em relação às chamadas "novas tecnologias" - do otimismo exacerbado, ao olhar mais crítico - e mais recentemente Luis Mauro Sá Martino (2015) em seu estudo compilatório sobre as teorias das mídias digitais, "digital" e "analógico" são contrapostos de modo a evidenciar a eficácia e a complexidade de uma lógica mediadora das nossas relações que se tornou não a única, mas a hegemônica nos últimos anos com

\footnotetext{
CASTELLS, 2013.
}

ADORNO, 1995. o advento dos computadores e da internet. Pode parecer trivial iniciar aqui por essa conceitualização, mas essa trivialidade se revela importante de ser recuperada quando percebemos que nela estão alicerçados nossos modos de aprender, interagir, se relacionar, pensar, agir, existir hoje.

No auge de seu otimismo em relação à internet, Levy (2010) nos apresenta o digital como a informação que foi traduzida em números - dígitos -, seja ela uma informação na forma de texto, imagem, ou som. "Quase todas as informações podem ser codificadas dessa forma", ${ }^{5}$ diz ele: as letras do alfabeto, as imagens e fotografias, os sons e músicas: toda informação que "pode ser explicitada ou medida, pode ser traduzida digitalmente". ${ }^{6}$ Mais à frente ele complementa: e "todos os números podem ser expressos em linguagem binária, sob a forma de 0 e 1 ". 7 Os números codificados em linguagem binária são gravados e transmitidos por dispositivos diversos (através de fios elétricos, circuitos eletrônicos, fitas magnéticas, fibras óticas, discos óticos, moléculas biológicas etc.) e, executados por circuitos eletrônicos especializados, são traduzidos em sentido inverso, manifestando-se como texto, imagem e som novamente. Esta é, também para Martino, uma das características principais do digital: "dados transformados em sequências de números interpretados por um computador". 8

A diferença em relação à forma analógica de comunicação de informações estaria, para Levy, principalmente na confiabilidade do digital e na possibilidade de reprodução e transmissão continuada sem o perigo de uma perda ou degeneração da informação: "A informação analógica é [...] representada por uma sequência contínua de valores. No entanto, a informação digital usa apenas dois valores, nitidamente diferenciados, o que torna a reconstituição da informação danificada incomparavelmente mais simples". ${ }^{9}$ Além dis-

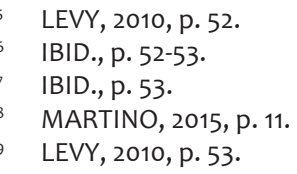


so, o processamento automático, rápido, preciso e em grande escala do digital representa, para Levy (2010), outra qualidade indiscutível. Martino (2015), por sua vez, aponta que a transformação de dados em números leva ao surgimento de uma série de características específicas inexistentes na tecnologia analógica e que passam a ser conceitos-chave, como: barreira digital, ciberespaço, convergência, cultura participativa, inteligência coletiva, interatividade, interface, segurança e vigilância, ubiquidade, velocidade e virtualidade.

No polo crítico da análise da hegemonia do digital está Deleuze, que relaciona o analógico às sociedades disciplinares, e o digital às sociedades de controle que "operam por máquinas [...] de informática e computadores"10 resultadas tanto de uma evolução tecnológica, quanto de uma mudança do capitalismo - que passa a ser não mais de produção, mas de sobreprodução - seu eixo pende da fábrica para o mercado de serviços. "[...] os diferentes modos de controle, os controlatos, são variações inseparáveis, formando um sistema em geometria variável cuja linguagem é numérica (o que não quer dizer necessariamente binária)" "11 e funcionam como uma modulação. Os computadores e demais dispositivos tecnológicos digitais presentes no nosso cotidiano atualmente não apenas operam pela linguagem numérica, como pela lógica binária. São os chamados computadores clássicos, que operam por bits de o e 1 .

Iniciativas no âmbito da inteligência artificial, por exemplo, aqueles no âmbito da linguagem natural ${ }^{12}$ e da lógica fuzzy,,$^{13}$ tentam superar esse binarismo seja por uma linguagem mais próxima ao cotidiano, seja estabelecendo modulações infinitas entre o e 1, inserindo a possibilidade de "capturar informações vagas", nem totalmente verdadeiras, nem totalmente falsas. Além disso, hoje a computação quântica já promete ser um "novo capítulo na revolução da informa-

DELEUZE, 2010, p. 227.

IBID., p. 225.

PEREIRA, S/D.

RIGNEL, CHENCI \& LUCAS, 2011. ção", pois opera para além dos dois estados o e 1, incluindo o 01 e o 10 (princípio de contradição/paradoxo), com a ideia de compreender os chamados "aspectos fundamentais da natureza". "A natureza computa", ${ }^{14}$ diz o vice-presidente da IBM. A IBM indica que em cerca de 10 anos teremos acesso a dispositivos quânticos capazes de provocar uma revolução no âmbito do conhecimento e construir uma sociedade muito mais avançada do que a atual com a ajuda de computadores mais inteligentes do que os seres humanos. ${ }^{15}$ Aqui a inteligência está ligada a ideia de calcular, de analisar e compreender o mundo através de modelos matemáticos e de ampliar exponencialmente o leque de fenômenos (naturais e sociais) que podem ser previstos e simulados com exatidão.

No dia 4 de maio de 2016, a IBM disponibilizou uma versão teste em nuvem de seu computador quântico. A empresa afirma que com ele:

Irrompe-se uma teoria totalmente quântica e uma tecnologia de processamento de informação que nos permitirá realizar alguns cálculos que levariam mais do que a idade do universo para serem realizados em um computador clássico; e processar informações de outras maneiras que são tão novas e diferentes que elas não podem nem mesmo ser devidamente descritas, muito menos realizadas, dentro do modelo clássico. A IBM Quantum Experience representa o nascimento da computação em nuvem quântica, oferecendo aos estudantes, pesquisadores e entusiastas da ciência acesso em nuvem à plataforma de computação quântica experimental da IBM, permitindo aos usuários executar algoritmos e experiências, o trabalho com bits quânticos (qubits), e explorar tuto-

\footnotetext{
14 https://www.youtube.com/ watch? $v=D Z 2$ DcILZAbM\&feature=youtu.be 15 https://www.youtube.com/watch?v=ENL5mpjDmZc
} 
riais e simulações em torno do que poderia ser possível com a computação quântica. ${ }^{16}$

A IBM Quantum Experience é um laboratório virtual, onde pesquisadores e curiosos podem executar seus algoritmos virtualmente, diretamente nos processadores quantum localizados em New York. É claro que os dados registrados nessa "livre utilização" se convertem em correções e aperfeiçoamentos na tecnologia; que pode ser adquirida por cerca de 15 milhões de dólares (embora ainda em testes). O Google é uma das empresas que já possuem esse computador. ${ }^{17}$ Não posso deixar de lembrar uma passagem da Dialética do Esclarecimento, em que os autores já nos avisam: "O que os homens querem aprender da natureza é como empregá-la para dominar completamente a ela e aos homens". ${ }^{18}$

Esta que apresento aqui é, obviamente, uma visão crítica do desenvolvimento tecnológico digital em nossa sociedade, ancorada principalmente na ideia de que as tecnologias existentes não podem ser consideradas neutras, mas sim carregadas de valores que definem - conscientemente ou não - modos e estilos de vida específicos; a tecnologia é estruturada e estruturante de estilos de vida. Feenberg (2013) apresenta quatro perspectivas contemporâneas concernentes à Filosofia da Tecnologia: o determinismo, que considera o desenvolvimento tecnológico neutro e autônomo, cujo sentido é sempre do avanço e aprimoramento na História; o instrumentalismo, que caracteriza certa visão usual moderna a partir de uma fé liberal no progresso perseguido por sujeitos livres que controlam a tecnologia; o substantivismo, que realiza uma crítica distópica a partir de uma visão ao mesmo tempo determinista, mas que avança sobre a não neutralidade da tecnologia; e a teoria crítica, que reconhece as consequências catastróficas do desenvolvimento tecnológi-

\footnotetext{
16 Tradução da autora. Texto original em: http://www. research.ibm.com/quantum/

17 http://climatologiageografica.com.br/o-google-estaabracando-o-computador-quantico/

18 HORKHEIMER \& ADORNO, 1985, p. 20.
}

co que temos, mas percebe a possibilidade de conquista de liberdade na tecnologia, por meio de uma intervenção democrática, cuja realização depende de um conhecimento histórico, político e técnico ${ }^{19}$ dos artefatos que medeiam a nossa existência. ${ }^{20}$

\section{MEIOS dE COMUNICAÇÃO E HISTÓRIA SOCIAL}

Historiadores dos meios de comunicação, como Armand e Michèle Mattelart (2002) e Tim Wu (2012), são unânimes em afirmar que desde o início dos tempos cada nova invenção relativa à comunicação foi acompanhada de entusiasmo e esperança no desdobramento de possibilidades de libertação: como "vetor

19 Aqui me aproximo da noção grega de Techné, que caracteriza um conhecimento que se associa a uma forma de poiesis (produção do mundo pelos seres humanos através de seus artefatos materiais, culturais, estéticos etc.) e que inclui um propósito orientador dessa produção, concebendo como indissociável a relação entre meios e fins, a produção da sociedade e o questionamento de seu objetivo. Concebo que, como apresentou Horkheimer (2002), na história do desenvolvimento tecnológico e científico da humanidade razão objetiva e razão subjetiva se dissociaram na busca de neutralidade e realização do progresso. Mas, esse percurso não ocorreu sem que fora preservada a valoração na ideia mesma de neutralidade. Rapidamente neutralidade passou a significar manutenção da estrutura social burguesa.

20 Avanço em relação ao que Feenberg (2010) propõe para uma Teoria Crítica da Tecnologia, na medida em que ele exclui dessa teoria pensadores como Theodor Adorno e Max Horkheimer, incluindo Herbert Marcuse, de quem foi estudante nos anos 1960. As contradições do pensamento do próprio Feenberg sobre sua proposta de uma Teoria Crítica da Tecnologia, que justifica sua escolha numa leitura bastante suspeita da Dialética do Esclarecimento e apenas nela e sua crítica habermasiana, será trabalhada de modo detalhado em outro momento. Por hora, é importante apenas frisar que, neste ensaio, não serão desconsiderados os trabalhos de Adorno e Horkheimer como pensadores de uma proposta Teoria Crítica da Tecnologia, na medida em que o olhar amplo para o projeto e a obra desses autores nos permite compreender que neles podemos encontrar não apenas a crítica a uma falsa neutralidade científica e tecnológica, mas apontamentos de possibilidades que foram pouco explorados por seus intérpretes e que podem nos ajudar a compreender que para eles a tecnologia é humana e historicamente dependente. 
de progresso e realização da razão". ${ }^{21} \mathrm{O}$ que foram as cruzadas, senão acesso a informações ao redor do mundo disponíveis para aqueles que tinham os mais avançados navios e sistemas de navegação? Não é por acaso que dizemos que "navegamos na internet". Em 1978, Al Gore já havia indicado: a internet é a "super-estrada da informação". ${ }^{22}$ Mattelart \& Mattelart (2002) nos lembram que isso também pode ser observado com as primeiras construções de estradas pela Europa no período da Revolução Industrial (Século XVIII) - vias fluviais, marítimas e terrestres por onde notícias e mercadorias poderiam chegar com mais facilidade de um ponto a outro do continente, propiciando, inclusive, a gestão das multidões que cresceram nas cidades.

O surgimento das tecnologias de comunicação sempre esteve ligado ao controle, à dominação, à administração e à gestão - inclusive com a imprescindível participação de intelectuais e pesquisadores de grandes universidades; a suposta neutralidade da ciência precisa ser sempre questionada - esse é, antes de qualquer coisa, um espaço político. 0 telégrafo, primeiro sistema de tecnologia de comunicação a distância, surgiu em 1793. Sua finalidade era militar (MATTELART \& MATTELART, 2002). A internet surgiu em 1963, no Pentágono (FEENBERG, 2010; WU, 2012). Ali, Licklider, um funcionário da Agência de Projetos de Pesquisas Avançadas do Departamento de Defesa Norte-americano, "imaginou uma grande rede universal pela qual as mentes de toda a humanidade poderiam se conectar via computadores", ${ }^{23}$ de modo que esta poderia realizar todo o seu potencial ao estabelecer uma ligação homem-máquina: o surgimento dos ciborgues. O computador passou a ser algo além de uma máquina de calcular, um auxiliar do homem nos processos de pensamento, um auxiliar analítico.

Do telégrafo à internet, da AT\&T ao Google, Wu (2012) nos apresenta uma dinâmica histórica das comunicações na era tecnoló-

21 MATTELART \& MATTELART, 2002, p. 14.

22 PINHO, 2002, p. 22.

23 WU, 2012, p. 207. gica em que cada nova invenção/descoberta desafia a anterior impondo-se como revolucionária, para em seguida, ao conquistar seu espaço de hegemonia, se realizar em monopólios. Nesse sentido, ele fala da construção de impérios: os Impérios da Comunicação.

Se olharmos com atenção o século $X X$, logo descobriremos que a internet não foi a primeira tecnologia da informação a mudar tudo para sempre. Na verdade, houve uma sucessão de mídias abertas e otimistas, mas cada qual, na devida época, tornou-se fechada e controlada por indústrias [...]. Nos últimos cem anos, muitas vezes a mudança radical prometida por novas formas de receber a informação parecia ainda mais drástica que a de hoje [...] Em sua época, cada uma dessas invenções - que deveriam ser o ápice de todas as demais - passou por uma fase de novidade revolucionária e utopismo juvenil: todas iriam mudar nossas vidas, sem dúvida, mas não a natureza de nossa existência. Seja qual for a transformação social que qualquer uma delas possa ter causado, no fim, todas ocuparam seu devido lugar na manutenção da estrutura social em que vivemos, desde a Revolução Industrial. ${ }^{24}$

Wu acredita em um padrão observável. Para ele, "a cada par de décadas, surge uma nova tecnologia da comunicação, cheia de promessas e possibilidades brilhantes. Ela inspira uma geração inteira a sonhar com uma sociedade melhor [...] Porém [...] acaba sempre por revelar seus pontos fracos" 25 - o principal deles tem sido a aliança constante entre Estado e força industrial dominante, capaz de "transformar uma tecnologia potencialmente destrutiva [da ordem atual] em ferramenta para perpetuar a dominação e adiar sua

24 IBID., p. 12.

25 IBID., p. 17 
morte". ${ }^{26} \mathrm{Wu}$ (2012) fala em termos de uma Indústria Cultural e da Informação, uma indústria que determina de antemão o que será dito e quem será ouvido.

Computadores em suas mais diversas formas como TV digital, tablets e Smartphones - além da crescente internet das coisas, também desenvolvida pelo Pentágono - não são somente meios de comunicação, mas dispositivos de informação: são máquinas de calcular que expandiram sua potencialidade analítica para "auxiliar" seres humanos, conectando-os a uma rede universal; talvez um cérebro universal. Eles oferecem informações analisáveis e analisadas em termos de modelos matemáticos e exigem de seu operador habilidade para se apropriar de sua lógica e utilizá-los de forma eficaz:

Assim como você é o que você come, o que você pensa ou a maneira como pensa dependem da informação a que estiver exposto. Como você ouve as vozes dos líderes políticos? De quem é a dor que você sente? De onde vêm suas aspirações, seus sonhos de uma vida boa? Tudo isso provém de um ambiente de informação. ${ }^{27}$

\section{SUBJETIVIDADES MEDIADAS PELO ARTEFATO}

Em uma direção bastante próxima de Wu (2012), Sherry Turkle (2004) afirma: “As ferramentas que usamos para pensar modificam o modo como pensamos". Em seu livro The Second Self: computers and the human spirit, ela nos diz:

[...] no mundo dos proprietários de computadores domésticos, no mundo de virtuosos programadores conhecidos como "hackers", e no mundo dos especialistas em inteligência artificial, uma comunidade dedicada ao empreendimento de construção de "máquinas pensantes" e teorias computacionais da mente, as pessoas assumiram que o computador sinaliza o desenvolvimento de algo novo. Esse "algo novo" assume muitas formas diferentes. A relação com um computador pode influenciar as concepções das pessoas sobre si mesmas, seus empregos, suas relações com outras pessoas, e com as suas maneiras de pensar sobre os processos sociais. Pode ser a base para novos valores estéticos, novos rituais, nova filosofia, novas formas culturais. $^{28}$

A linguagem computacional é a da lógica matemática. Aquela considerada por filósofos, como Leibniz e Descartes, e por teóricos bastante estudados em Psicologia do desenvolvimento, como Piaget, a própria razão. Valerie Walkerdine (1988) denuncia o engodo dessa formulação. Para ela, a lógica matemática, considerada "razão natural", é, na realidade, produzida com o intuito de levar à dominação da razão e da pessoa "racional". A "razão natural" é, ela mesma, uma interpretação, uma representação, uma verdade produzida na relação entre as práticas matemáticas e discursivas (WALKERDINE; 1988). A autora questiona a confiança na dominação do mundo físico, a ideia de autonomia independente e de governo racional. Quando nos deparamos, contudo, com a realidade do que podemos chamar de um mundo digital, percebemos que essa é a lógica que se enraíza a partir de um processo de desenvolvimento histórico, político e econômico - na sociedade e seus membros hoje. Tal lógica não é a única existente nem foi a única produzida pelos pensadores e grupos humanos ao redor do mundo, mas se tornou hegemônica, descartando possibilidades outras de representação da realidade que foram consideradas mito, crença, ou pura irracionalidade, ou que simplesmente demonstraram menos "eficácia" na solução dos problemas que criamos.

\footnotetext{
26 IBID., p. 39.

27 IBID., p. 21.
}

28 TURKLE, 2005, p. 156, tradução da autora. 
Nesse sentido, Turkle (2005) nos diz que o computador pode ser visto como um catalisador de cultura. Ele estimula e incentiva a expansão da própria lógica que o gerou, alargando suas consequências em termos das possibilidades de experiências subjetivas. A autora aponta essas consequências em um sentido bastante similar a Adorno (2009), que derivou características de uma geração do rádio a partir das propriedades desse aparato, pensando a existência de uma mudança antropológica que ocorreria a partir dos avanços tecnológicos e das características dos meios de comunicação deles derivados. A perda da capacidade imaginativa/intuitiva, a fetichização dos aparatos e a adaptação irrestrita dos sujeitos a eles, já haviam sido apontadas na geração do rádio, ao lado da perda da capacidade de expressão pela linguagem, da desintegração da autoridade familiar e da relação técnica da pessoa com seu próprio corpo, num processo de reificação: "Ele é o tipo de pessoa cujo ser está no fato de que ele não mais experiencia qualquer coisa por si mesmo, mas deixa o aparato todo poderoso e opaco ditar todas as experiências para ele". ${ }^{29}$

Para Adorno, teriam sido cinco as mudanças na esfera social que propiciaram o desenvolvimento desse novo tipo antropológico:

1. A falta de imagens artísticas oferecidas às crianças, que não imagens técnicas como as de carros, aviões etc. - isso porque para Adorno o processo de sublimação é impossibilitado pela ausência de um repertório objetivo de imagens com as quais dialogar e o arrefecimento desse repertório objetivo seria acompanhado pela diminuição da imaginação subjetiva - o que manteria as pessoas dentro dos limites do existente. Além disso, o definhamento do mundo das imagens seria acompanhado pelo da linguagem e da capacidade de expressão por essa via.

2. A diminuição do número de objetos sob os quais os homens operariam uma ação real. A mecanização dos objetos força o sujeito a se adaptar, a se subordinar aos instru-

29 ADORNO, 2008, p. 465, tradução da autora. mentos de uso cotidiano - o que inclui aqueles utilizados no tempo livre.

3. Mudança estrutural no processo de trabalho, no qual a prática ou a experiência foram substituídas pela quantificação e pela reificação dos processos, o que inclui os trabalhos intelectuais.

4. Desintegração da autoridade familiar, o que atinge o desenvolvimento infantil em sua profundidade. Na medida em que a família não é mais a agência mediadora entre a sociedade e o indivíduo, deixando de ser seu escudo projetivo, a sociedade tem se aproximado do sujeito de forma direta, dificultando sua formação mesma.

5. Quantificação tecnológica do corpo gerada pela mudança na relação estabelecida entre as pessoas e seus próprios corpos.

Turkle (2004) aponta, contudo, que com os computadores se sedimenta ainda mais a dificuldade de reconhecer a possibilidade de existência da ambivalência/conflito, que passa a ser compreendida apenas como um erro no processamento de informação, quando se pensa o cérebro humano como correlato ao sistema computacional clássico. O problema no "significado" é substituído por um problema de "mecanismo". A psicóloga social do MIT relembra nesse momento a intervenção de uma estudante em uma das primeiras disciplinas que ministrou como professora ali, na década de 1970 . Eles estavam trabalhando em sala de aula o livro Sobre a psicopatologia da vida cotidiana, e discutiam o exemplo em que o presidente do parlamento austríaco abria a sessão da seguinte forma: "Senhores Deputados; Constato a presença dos membros dessa casa em quorum suficiente e, portanto, declaro encerrada a sessão!"30 Para Freud (2006), o lapso cometido pelo presidente, que trocara "aberta" por "encerrada", resulta de uma contradição no interior dele mesmo, na medida em que ele desejava em segredo encerrar a sessão. Mas, a estudante não aceitou essa interpretação e ofereceu sua própria leitura do caso, a partir da ideia de que o cé-

30 FREUD, 2006, p. 43-44. 
rebro humano funciona a partir das mesmas regras da computação: ${ }^{31}$

A mente, ela argumentou, é um computador. E, em um dicionário computacional - como nós temos na mente humana - "aberta" e "encerrada" são designadas pelo mesmo símbolo, separadas por um sinal de oposição. "Encerrado" equivale a "menos iniciado". Substituir "encerrada" por "aberta" não requer a noção de ambivalência ou conflito. "Quando o presidente fez essa substituição", ela disse, "um bit caiu, um sinal de menos foi perdido. Houve uma oscilação de energia. Sem problema." ${ }^{2}$

A dificuldade em lidar com um mundo incompreensível e repleto de contradições que se sedimentam subjetivamente já havia sido revelada por Adorno et al. (1969), no estudo sobre a personalidade autoritária, como consequência de um processo semiformativo em que a informação - na forma de clichês - apa-

31 Aqui a estudante se referia à computação clássica. Possivelmente, uma forma diferente de ver o cérebro humano como um computador possa emergir das linguagens de computação quânticas, onde a contradição - na forma da possível superposição dos valores o e 1-tem papel importante. As consequências dessa lógica de cálculo modificada nas formas como compreendemos quem somos e nos comportamos frente a isso precisam ser investigadas. É certo que a computação quântica é ainda digital e é preciso verificar os tipos de contradições possíveis e suas formas de solução. A limitação da implementação dos computadores quânticos não demorará a ser superada. Será que, como no filme norte-americano de ficção científica “Her” (JONZE, 2013), aprenderemos com a máquina e superaremos nós mesmos? Ou, como nos mostra a história dos meios de comunicação, a superação será bloqueada pelo modo de produção que sustenta e fomenta essa tecnologia desde sua base material e racional? Não seria surpreendente se, num futuro cuja semente já brota no agora, esse tipo de tecnologia aprofundasse a problemática da pós-verdade - mas quanticamente criada a partir do controle irrestrito dos computadores quânticos sobre a política, e economia e o conhecimento - tornando-a hegemônica nas (falsas)consciências e ações.

32 TURKLE, 2004, p. B26, tradução do autor. rece como substituta da reflexão sobre a própria sociedade por meio do esquematismo adjacente aos mecanismos da Indústria Cultural. No mundo digital - que reconhecemos como expansão daquela indústria -, essa questão parece apontar que a lógica booleana e os silogismos aos quais o computador responde com o ou 1, falso ou verdadeiro, aprofundam essa problemática e torna como que "natural" a justificativa da suposta inexistência de contradições - a unidimensionalidade aparece como resultado de um binarismo naturalizado na reificação de si mesmo sob a justificativa da mais desenvolvida racionalidade.

Além disso, para a autora, a tecnologia computacional encoraja mudanças no pensamento em seis áreas: 1 . Na concepção de privacidade e naturalização da "transparência"; 2. Na confusão entre avatares/personagens e si mesmo; 3. Na substituição do conteúdo pela produtividade (cultura do PowerPoint - e hoje, Prezi); 4. Na substituição do pensar pelo processamento de palavras (diferença entre escrever na máquina ou a mão e no computador); 5. Na valorização de uma transparência na interface que corresponde a uma opacidade epistêmica (não precisamos saber como funciona o computador, contanto que seu uso seja “intuitivo”); e 6. Na simulação e seu mal-estar - na passividade gerada por essa opacidade; na medida em que ela deixa subentendido que "nossas ferramentas carregam mensagens que estão além do nosso entendimento".

Segundo Turkle, "as simulações computacionais por um lado habilitam seus usuários a pensar sobre fenômenos complexos como dinâmicos. Mas, por outro, elas também nos habituam a sistemas manipulativos cujas ideias principais nós não entendemos e que podem não ser verdade". ${ }^{33}$ Os jogos de videogame são um exemplo desse caso: eles nos habilitam a desenvolver o raciocínio a partir de uma configuração de problemas que devem ser transpostos, mas atuam dentro da dicotomia medo/ segurança - perigo/dominação.

33 IBID, p. B26, tradução da autora. 
Adorno chamou os ouvintes de "geração do rádio"; Turkle chama os sujeitos contemporâneos de computer people - para ela, as tecnologias da informação são tecnologias de identidade. Se, inicialmente essa nomenclatura era utilizada para denominar aqueles que trabalhavam diretamente com programação, hoje ela diz respeito ao conjunto daqueles que vivem em uma sociedade da informação tecnológica e digital, e que, mesmo como "usuários" atuam de forma definitiva na expansão e na manutenção de sua lógica e existência.

\section{CONSIDERAÇÕES FINAIS}

É apenas aparente o descompasso entre o desenvolvimento tecnológico e científico, e o desenvolvimento humano. O desenvolvimento dos sujeitos nessa sociedade acompanha o desenvolvimento técnico e científico em seu interior - apenas aqueles que acreditam na mais ampla racionalidade desse sistema podem ainda se surpreender com seus resultados em termos humanos (e também sociais, e também ecológicos). Como Marcuse (2015) apontou em suas aulas de Paris de 1974, a nova subjetividade produzida pelo capitalismo protoliberal é mais eficientemente integrada na produção do próprio capitalismo: a consciência está no nível das condições objetivas.

Isso não significa que as pessoas são "dóceis" ou que não há mais luta de classes, luta por construir um mundo da liberdade. É verdade que a luta de classes é gerenciada pelas grandes corporações, mas Marcuse reconhece a necessidade de uma consciência radical que seja capaz de se colocar à frente das condições objetivas e antecipar possibilidades. Contudo, essa consciência, para não se realizar também como falsa consciência, não pode se recusar a ver as mudanças efetivamente ocorridas na sociedade e no capitalismo. Ela deve partir de si mesma.

No mesmo trabalho em que descreve a geração do rádio, Adorno afirma:
Há uma razão para assumir que a perda de algumas habilidades é acompanhada da liberação de outras, e isso é precisamente o que as leva a executar mudanças que nunca teriam sido possíveis para os antigos "indivíduos". A quebra do muro monadológico, que encerrava cada indivíduo dentro de si mesmo na era liberal, é a maior fonte de esperança. ${ }^{34}$

Adorno pensa em termos de uma educação que leve em consideração os aparatos mediadores e o conhecimento de suas características, colocando-os de modo claro, investigando suas consequências e não inebriando seus "usuários" a respeito de sua pretensa qualidade emancipatória intrínseca. Apenas através do reconhecimento sistemático e sincero desses aparatos poderemos libertá-los e libertar-nos de seus/nossos próprios mitos. Turkle (2004) fala em termos de reconstruir a cultura em torno da tecnologia da informação, uma nova cultura na qual as ideias sobre a natureza da dominação não sejam absolutas e na qual sejamos capazes de superar os binarismos. Feenberg (2010) aponta para a necessidade de uma democratização na esfera tecnológica. Para ele, grupos sociais caracterizados por minorias podem e devem se utilizar da rede de computadores como esfera pública na luta por direitos.

Contudo, quando hoje vemos nas redes sociais virtuais expressões do mais alto grau de conservadorismo e fascismo - mesmo entre aqueles que se pretendem libertários -, não podemos nos esquecer desses apontamentos - da relação bastante próxima que capitalismo e fascismo desenvolveram histórica e filosoficamente. "'Quem não quer falar do capitalismo deveria calar-se também a respeito do fascismo', disse Max Horkheimer se opondo às tentativas de teorizar sobre o nacional-socialismo sem ver sua íntima relação com a forma de produção capitalista." 35 Quem não quer falar

34 ADORNO, 2009, p. 465-466, tradução da autora.

35 GANDLER, 2009, p. 107. 
sobre o capitalismo, deveria calar-se também em relação à violência e ao sectarismo, à dessensibilização e à frieza burguesa que tanto se faz ver nas interações digitais.

É preciso falar, por fim, que uma Teoria Crítica da tecnologia precisa reconhecer as contradições de seu objeto. A apresentação continua sendo base importante para análise. Por meio dela ficamos atentos às armadilhas de um pensamento entusiasta, mas também de um determinismo sem saída. Não é disso que se trata. $O$ destino da humanidade depende de nossa influência direta na sociedade, e essa influência se realiza como práxis na medida em que transformações se tornam possíveis também na consciência. A gestão das massas apenas é um fato, porque delas vêm a real determinação da sociedade. Volto aqui, mais uma vez, a Marcuse (2015). Se o poder decisório sobre o destino da humanidade não estivesse nas mãos da grande maioria da po- pulação, tanta tecnologia não precisaria ser desenvolvida para manter essa maioria submetida a determinados padrões de pensamento e ação.

A modificação da internet por usuários - para além do controle dos especialistas pode levar a um potencial latente que desconhecemos? A abertura dos meios não deixa de ter interesses tanto comerciais, quanto humanitários. Existem, de fato, grupos que operam na rede na direção de "repolitizar" a tecnologia; a revolução está sempre latente. $\mathrm{O}$ que falta para a realizarmos? Aponto aqui para a ideia de que a revolução no âmbito tecnológico precisaria não apenas ser crítica, mas principalmente estética, pensando na associação entre Logos e Eros, que tão belamente Adorno (1997) aponta como necessária em sua Teoria Estética, para a realização de um conhecimento liberto, lúdico e comprometido com a vida.

\section{REFERÊNCIAS}

ADORNO, T. W. Tempo Livre. In: Adorno, T. W. Palavras e sinais: modelos críticos 2. Petrópolis: Vozes, 1995.

Press, 1997.

Aesthetic Theory. Trad. Robert Hullot-Kentor. Minneapolis: University of Minnesota

. The problem of a new type of human being. In: Current of music. Cambridge/Malden: Polity Press, 2009.

. FRENKEL-BRUNSWIK, E.; LEVINSON, D. J.; SANFORD, R. N. The authoritarian personality. New York: WW Norton, 1969.

BERI, C.; TELLO, C. La interdisciplinariedad como "contrafuego" al neoliberalismo académico. IV Jornadas de Sociología de la UNLP, 23 al 25 de noviembre de 2005. La Plata, Argentina. La Argentina de la crisis: Desigualdad social, movimientos sociales, política e instituciones. En Memoria Académica. Disponível em: http://www.memoria.fahce.unlp.edu.ar/trab_eventos/ev.6673/ ev.6673.pdf. Acessado em 23/10/2016.

CASTELLS, M. Posfácio à edição brasileira. In: Redes de indignação e esperança: movimentos sociais na era da internet. Rio de Janeiro: Zahar, 2013.

DELEUZE, G. Post-scriptum sobre as sociedades de controle. In: Conversações (1972-1990). São Paulo: Ed. 34, 2010.

FEENBERG, A. Bases teóricas para a democratização e a filosofia da tecnologia. In: Ciclo de Conferências Teoria Crítica da Tecnologia - Parte 1. Brasília: UNB, 2010. Disponível em https://www. youtube.com/watch?v=2ofaot-XAsw. Acessado em 24/10/2016.

FEENBERG, A. O que é filosofia da tecnologia? In: Ricardo T. Neder (Org.). A teoria crítica de Andrew Feenberg: racionalização democrática, poder e tecnologia. Brasília: Observatório do Movimento pela Tecnologia Social na América Latina / CDS / UnB / Capes, 2013 (2. ed.). 
FREUD, S. Sobre a psicopatologia da vida cotidiana [1901]. Rio de Janeiro: Imago, 2006.

GANDLER, S. Fragmentos de Frankfurt: ensayos sobre la Teoría Crítica. México: Siglo XXI, 2009. HORKHEIMER, M. Eclipse da Razão. Trad. Sebastião Uchoa Leite. São Paulo: Centauro, 2002. HORKHEIMER, M.; ADORNO, T. W. Dialética do Esclarecimento: fragmentos filosóficos. Rio de Janeiro: Zahar, 1985.

IBM Quantum Computing. Disponível em http://www.research.ibm.com/quantum/. Acessado em 24/10/2016.

JONZE, S. [Dir.] Her. (Filme). Hollywood: Warner Bros. Pictures, 2013.

LÉVY, P. Cibercultura. São Paulo: Ed. 34, 2010.

MARTINO, L. M. S. Teoria das mídias digitais: linguagens, ambientes e redes. Petrópolis: Vozes, 2015.

MATTELART, A.; MATTELART, M. História das teorias da comunicação. São Paulo: Edições Loyola, 2002.

PEREIRA, S. L. Processamento de linguagem natural. s/d. Disponível em: http://www.ime.usp. br/ slago/IA-pln.pdf. Acessado em 23/10/2016.

PINHO, J. B. Relações públicas na internet: técnicas e estratégias para informar e influenciar públicos de interesse. São Paulo: Summus, 2002.

PUELLO-SOCARRÁS, J. F. Un ensayo sobre la depravación total. Nuevo Neoliberalismo Académico y Capitalismo 'por posesión'. In: Revista Izquierda, n. 14, ago. 2011. Disponível em http:// www.espaciocritico.com/sites/all/files/izqrd/no014/izq0014_a03.pdf. Acessado em 23/10/2016.

RIGNEL, D. G. S.; CHENCI, G. P.; LUCAS, C. A. Uma introdução à lógica fuzzi. In: Revista Eletrônica de Sistemas de informação e gestão tecnológica, v. 1, n. 1, 2011. Disponível em http://www. logicafuzzy.com.br/wp-content/uploads/2013/04/uma introducao_a logica_fuzzy.pdf. Acessado em 23/10/2016.

TURKLE, S. How computers change the way we think. In: The chronicle of higher education, v. 50, Issue 21, p. B26, 30 jan. 2004. Disponível em http://www1.udel.edu/educ/whitson/897505/ files/turkle. Acessado em 24/10/2016.

. The second Self: computers and the human spirit. Cambridge/London: MIT Press, 2005.

WALKERDINE, V. The mastery of reason: cognitive development and the production of rationality. London/New York: Routledge, 1988.

WU, T. Impérios da comunicação: do telefone à internet, da AT\&T ao Google. Rio de Janeiro: Zahar, 2012.

\section{DADOS DA AUTORA}

\section{Deborah Christina Antunes}

Doutora em Filosofia pela Universidade Federal de São Carlos. Professora Adjunta do curso de Psicologia da Universidade Federal do Ceará. Fortaleza/CE - Brasil deborahantunes@ufc.br

Submetido em: 10-4-2017

Aceito em: 31-7-2017 